\title{
PATTERN ANALYSIS OF TURKISH BREAD WHEAT LANDRACES AND CULTIVARS FOR GRAIN AND FLOUR QUALITY
}

\author{
Mevlut AKCURA ${ }^{1^{*}}$, Kagan KOKTEN ${ }^{2}$, Aysun GOCMEN AKCACIK ${ }^{3}$, Seydi AYDOGAN ${ }^{3}$ \\ ${ }^{1}$ University of Çanakkale Onsekiz Mart, Faculty of Agriculture, Department of Field Crops, Çanakkale, \\ TURKEY \\ ${ }^{2}$ University of Bingol, Faculty of Agriculture, Department of Field Crops, Bingol, TURKEY \\ ${ }^{3}$ Bahri Dagdaş International Agricultural Research Institute, Konya, TURKEY \\ *Corresponding author: makcura@comu.edu.tr
}

Received: 05.08.2015

\begin{abstract}
This research was carried out to characterize both 200 pure lines selected from Turkish bread wheat landraces and 25 Turkish bread wheat cultivars based on 3 grain quality traits [thousand kernel weight (TKW), protein content (PC), Zeleny sedimentation test (ZSDS)] and 5 mixograph parameters. Univariate and Multivariate (clustering and ordination) techniques were used to investigate the diversity present among the pure lines and cultivars. Both cluster and ordination analyses suggested that there were ten groups of studied genotypes. Applying genotype-by-trait (GT) biplot analysis to the multiple quality trait data revealed that GT-biplot graphically displayed the interrelationships among traits and facilitated visual comparison of pure lines and selection. The results also showed that, based on the quality traits, the pure lines in different groups were belonged to different provinces of Turkey. They were also proved to be highly diverse for 8 quality trait values (both mixograph and grain quality) to breeders and end-users. Especially most of the pure lines had higher PC, midline peak value of mixogram (MPV), midline time $x=8$ min integral of mixogram (MTxI) and ZSDS values than some of the cultivars. Also, our results were very contributive in selection of precious pure lines for further breeding programs.
\end{abstract}

Key Words: Landraces, Mixograph, Pattern Analysis, Pure Lines, Quality Traits, Turkey

\section{INTRODUCTION}

A landrace may display variation for many traits, because of natural selection and by traditional farmers to a limited extent in the environment, where it is inhabited, due to its admixtured genotypes (Belay et al. 1995; Jaradat 2006; Ahmadizadeh et al. 2011). Wheat landraces comprise the major genetic resource of cultivated wheat in Turkey (Akcura 2011).

Germplasm collections continue to play a vital role in providing the genetic resources needed for improving bread wheat. During the last 70 years of the $20^{\text {th }}$ century, an individual study resulted in collecting and conserving these landraces in gene banks; their vernacular names and some of their characteristics have been documented (Gokgol 1939). As distinct plant populations, landraces are named and maintained by traditional farmers to meet their social, economic, cultural, and environmental needs. Bread wheat landraces, in Turkey, also may be classified according to expected usage; different landraces are used for flour, bulgur, lavas, tandir, asure etc. Consumption attributes of a variety are reported to be important for a farm household, on farm cultivation is the best solution to guarantee its availability (Brush and Meng 1998). Wheat landraces, such as Kirik, is still grown in some areas of Eastern Anatolian Region, especially, in the least favorable areas. Advantages of Kirik landrace can be listed, in East Anatolia, as high quality and white grain for white unleavened lavash bread, a high value marketable product locally, short growing season, facultative wheat, low risk of production, good straw, no awns (Bardsley and Thomas 2005; Karagoz 2013). Similarly, Asure is a landraces is grown in Elazig and Malatya provinces, its grains are sought for asure dessert. Genetic variation of Turkish bread wheat landraces different traits such as biochemical characters, endosperm proteins and isoenzymes studied by some scientists (Ozkan et al. 1998; Peskircioglu et al. 1998; Karcicio and Izbirak 2003; Ozbek et al. 2011; 2012). Genetic variability and interrelationship among grain yield and some quality traits in Turkish wheat landraces evaluated by Akcura (2009) and Sayaslan et al. (2012). In addition, Turkish durum wheat (Akcura 2009; Sayaslan et al. 2012) and bread wheat (Akcura and Topal 2006; Kara and Akman 2007) landraces were assessed to determine the genetic diversity by several authors according to some quality related morphological traits.Turkish wheat landraces have a great potential to have different traits such as grain yield, yield component and some quality traits for rainfed breeding programs. Although 
Turkish bread wheat landraces have all these great breeding potential, nevertheless, they were not used broadly in breeding programs nationally (Akcura 2006; Akcura 2011; Ozbek 2013).

Germplasm evaluation and variety selection must be based on multiple traits or breeding objectives. For most crops, although yield is the first primary breeding objective, quality is also a very important point. Furthermore, quality is not a single trait; rather, it is measured by many characteristics, which may be negatively associated. Also, quality means different things for different end-uses (Yan and Fregeau-Reid 2008). Different methods have been used to evaluate the data structures, although strategies may differ in overall fitness, these methods usually lead to the same or similar conclusions for a given dataset (Flores et al. 1998; Rubio et al. 2004; Akcura 2011). Alternative statistical methods, ranging from simple univariate to the more complex multivariate techniques, have been used in the analysis of description of data in the durum wheat landraces of Iran (Aghaee et al. 2010). Pattern analysis techniques have been used broadly to evaluate the diversity among genetic material of different plant (Harch et al. 1995; Jahufer et al. 1997; DeLacy et al. 2000; Rosso and Pagano 2001; Aghaee et al. 2010). In addition to clustering technique, the genotype-by-trait (GT) biplot has been applied to understand the relations among traits and the trait profiles of the genotypes, particularly among those that are key breeding objectives (Yan and Kang 2003; Rubio et al. 2004; Peterson et al. 2005; Yan and Fregeau-Reid 2008; Yan 2014). Furthermore, GGT is an application of the GGE biplot to evaluate genotype comparison, and selection for different traits (Yan and Kang 2003; Ilker et al. 2009; 2011; Yan 2014).

However, Turkey is one of the main centers of very little work on quality and rheology of landraces has been carried out so far, so the present study was planned to investigate the quality and rheology in both 200 pure lines selected from Turkish bread wheat landraces and 25 widely growing Turkish bread wheat cultivars by using mixograph tests and to find out the relationships with different quality attributes.

\section{MATERIALS AND METHODS}

\section{Plant Material}

Totally 225 bread wheat genotypes (200 landraces pure lines and 25 registered Turkish bread wheat cultivars) were used as the experimental plant material. These pure lines were selected from 340 bread wheat landraces by pure line selection method between 2002-2005 growing seasons at Konya Location in Turkey (Akcura 2006). Origins of landrace pure lines were given at Figure 1. Other experiment materials were consisted of 25 cultivars (Altay2000, Bagci-2002, Bayraktar-2000, Bezostaja-1, Dagdas94, Demir-2000, Dogu-88, Flamura-85, Gelibolu, Gerek79, Gun-91, Harmankaya-99, Karahan-99, Kenanbey, Kirac-66, Kirgiz-95, Kirik, Konya-2002, Mufitbey, Pehlivan, Seval, Sonmez-01, Tekirdag, Tosunbey, Zencirci-2000). The field experiments were carried out under rain fed conditions at Canakkale Onsekiz Mart University, Dardanos Campus field experiment area in 2012 and 2013 growing seasons. The plant materials (225 genotypes) were sown in 4 rows of $2 \mathrm{~m}$ long incomplete block design with two replications. Sowing was done on first week of October in both growing seasons. Weeds were controlled manually. Fertilizer application was $27 \mathrm{~kg} \mathrm{~N}^{-}$ ${ }^{1}$ and $69 \mathrm{~kg} \mathrm{P}_{2} \mathrm{O}_{5} \mathrm{ha}^{-1}$ at sowing, $43 \mathrm{~kg} \mathrm{ha}^{-1} \mathrm{~N}$ was applied at the end of tillering stage in both growing seasons. Experiments were harvested near the same date between June 16 and June 28 for each year.

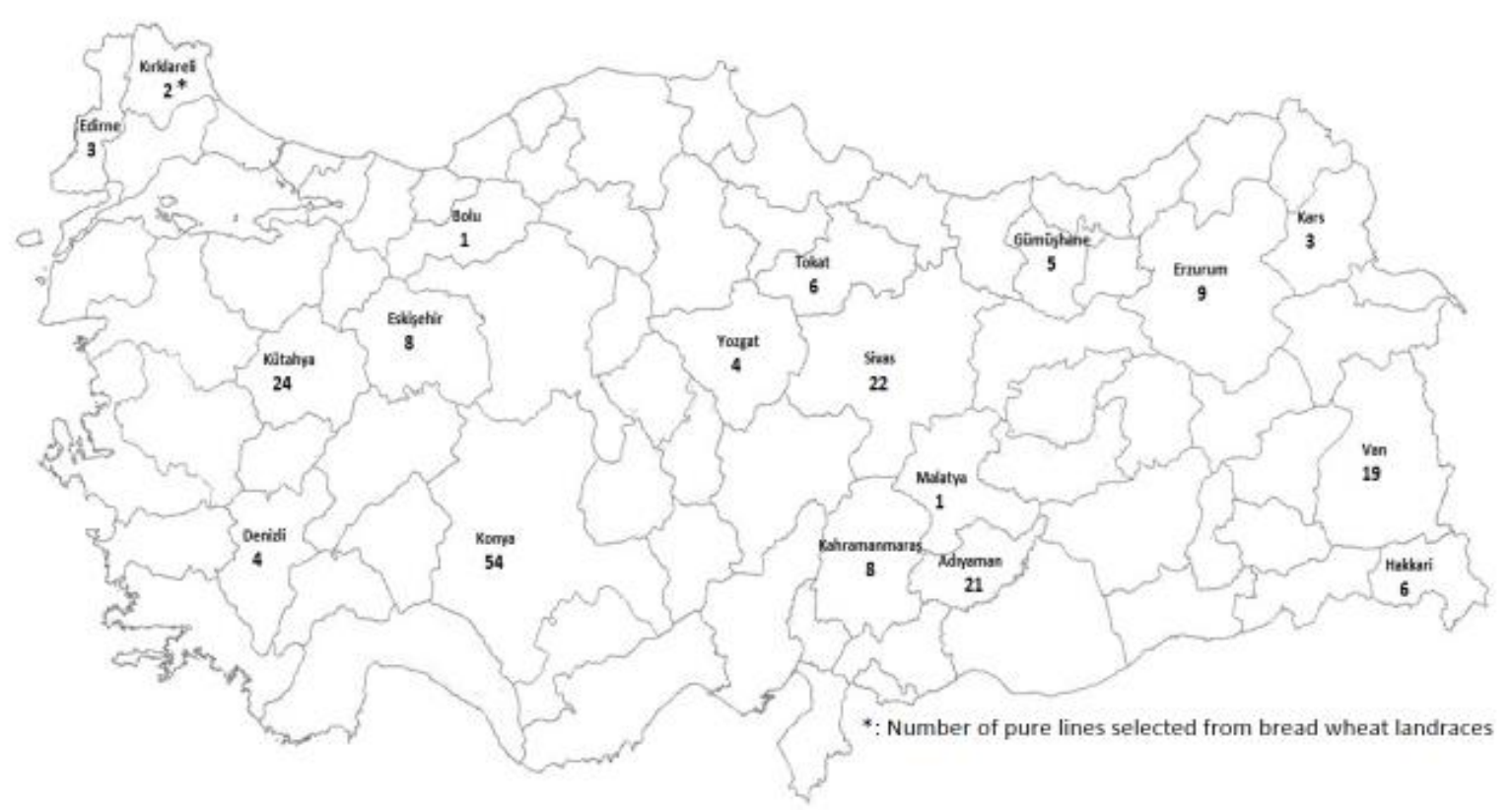

Figure 1. Origin of pure lines selected from Turkish bread wheat landraces 
Grain samples were dried and cleaned before quality analysis commenced. Quality analyses were performed on the complete set (200 pure lines, 25 cultivars and two replicates) of samples both seasons.

\section{Grain quality characteristics}

Thousand grain weights (TKW) of each wheat genotype were determined as described by Akcura (2011). The Zeleny sedimentation test volumes (ZSDS) were determined according to the method of AACC method 5681 and International Association of Cereal Chemistry standard method 115-116 (AACC 2000). Grain protein content (PC) was determined with a LECO FP-2000 (Leco Corporation Michigan USA).

\section{Flour Rheology}

To test dough quality, flour was obtained with the Chopin Dubois CD1 mill, which gave a $70 \%$ extraction rate. To assess dough properties during mixing, the mixograph test was done on $10 \mathrm{~g}$ of flour with added water, according to the approved AACC method 54-40A (AACC 2000). The mixograph curves (two envelopes and one midline) were computed with Mixsmart software. The software used the top envelope curves and the midline to analyze mixograms. The height of the curves and the width of the mixogram were recorded at three time points: at peak time, 8 min after peak time and at the end of the mixing procedure (10 $\mathrm{min})$. Five parameters, previously described by Martinant et al. (1998), Bordes et al. (2008) and Neacsu et al. (2009), were used. Two parameters were the height and the width of curves: at peak time (midline peak value (MPV)) and at $8 \mathrm{~min}$ (midline time $\mathrm{x}=8 \mathrm{~min}$ value $(\mathrm{MTxV}))$. The other parameters were the peak time (midline peak time (MPTi)) and the area under the midline curve after 8 min of mixing (midline time $\mathrm{x}=8$ min integral (MTXI)). Dough weakening was expressed as the difference in the curve heights at peak time and after 8 min of mixing; this parameter was called the weakening slope, WS = MPV - MRV (Bordes et al. 2008).

\section{Statistical analysis}

Pattern analysis, defined by Williams (1976) as the joint use of classification and ordination methods, was applied to characterize 225 genotypes (200 pure lines selected from bread wheat landraces and 25 cultivars) mean of data across growing seasons (DeLacy et al. 1996).

Both genotype-by-trait (GT) and genotype group-bytrait (GGT) biplots were used to assess the patterns of relations among quality characters, genotypes and their interactions. Biplots (Figure 2 and 3 ) were conducted in the dimension of first two principal components (PC1 and PC2), using a singular-value decomposition procedure (Gabriel 1971; Kempton 1984; Yan 2014). The CROPSTAT statistical software and biplot Macro for Excel were used to generate all statistical analyses (Lipkovich and Smith 2002; IRRI 2013).

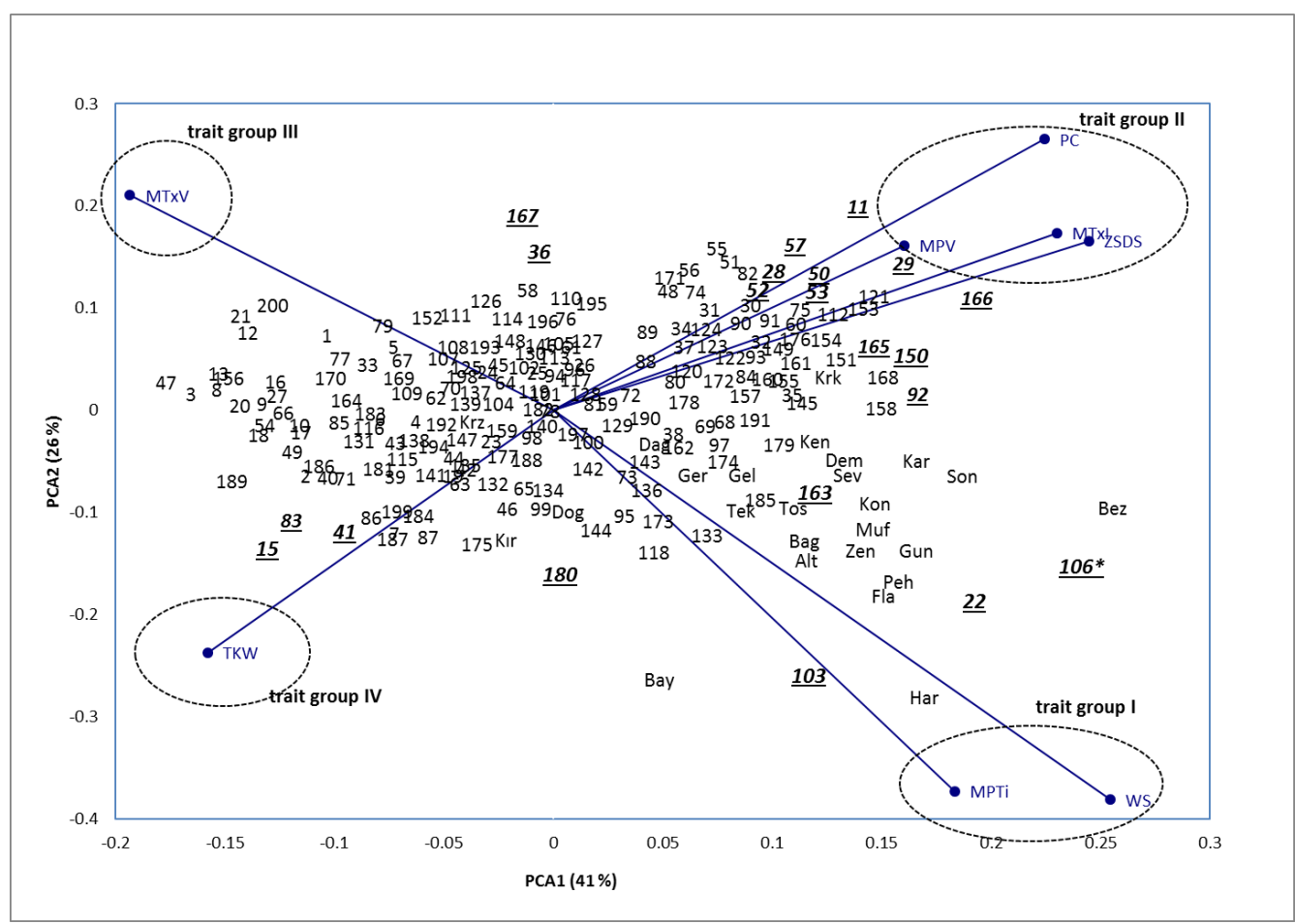

[*: The best lines; TKW: Thousand grain weight (g); ZSDS: Zeleny sedimentation test volume (ml); PC: protein content (\%); MPV: midline peak value (\%); MTxV: midline time $\mathrm{x}=8$ min value (\%); MTxI: midline time $\mathrm{x}=8 \mathrm{~min}$ integral (Tq\%*min); MPTi: midline peak time (min); WS: weakening slope (min); Cultivars abbreviation: Alt: Altay-2000, Bag: Bagci-2002, Bay: Bayraktar-2000, Bez: Bezostaja-1, Dag: Dagdas-94, Dem: Demir-2000, Dog: Dogu-88, Fla: Flamura-85, Gel: Gelibolu, Ger: Gerek-79, Gun: Gun-91, Har: Harmankaya-99, Kar: Karahan-99, Ken: Kenanbey, Kir: Kirac-66, Krz: Kirgiz-95, Krk: Kirik, Kon: Konya-2002, Muf: Mufitbey, Peh: Pehlivan, Sev: Seval, Son: Sonmez-01, Tek: Tekirdag, Tos: Tosunbey, Zen: Zencirci-2000]

Figure 2. Genotype by quality trait (GT) biplot of 225 genotypes across growing seasons 


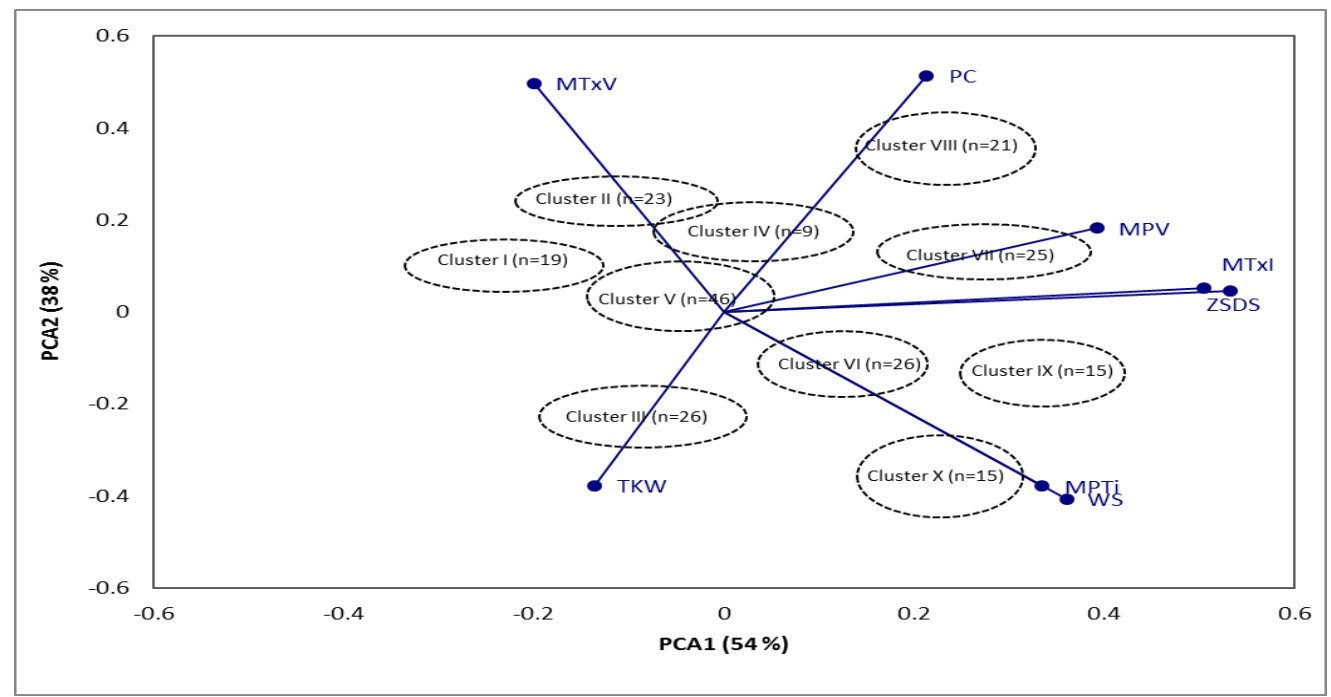

[TKW: Thousand grain weight (g); ZSDS: Zeleny sedimentation test volume (ml); PC: protein content (\%); MPV: midline peak value (\%); MTxV: midline time $\mathrm{x}=8 \mathrm{~min}$ value (\%); MTxI: midline time $\mathrm{x}=8 \mathrm{~min}$ integral (Tq\%*min); MPTi: midline peak time (min); WS: weakening slope (min)]

Figure 3. Group by trait biplot of ten genotype clusters

\section{RESULTS}

\section{Mean performance of genotypes}

Data recorded on the 225 bread wheat genotypes (200 landraces pure lines and 25 cultivars) across growing seasons for the quality and rheological traits were given in Table 1. For each trait the descriptive statistics were also presented in Table 1. Data in Table 1 indicated that all studied quality traits were remarkably influenced by genotypes (Data not given). In pure lines from landraces, the CV\% of the traits varied from $6.98 \%$ (for PC) to $40.09 \%$ (for MTxV). The lowest CV-values were observed for the traits PC followed by MPV, MTxI and TKW indicating the least variation among the all pure lines for these traits, while the highest values were found for the MTxV, WS, MPTi and ZSDS.

Table 1. Descriptive statistics of traits across growing seasons ( $n=200$ for pure lines, $n=25$ for cultivars)

\begin{tabular}{llllll}
\hline & \multicolumn{5}{c}{ Pure Lines Selected from Turkish Bread Wheat Landraces ${ }^{\S}$} \\
\hline Traits & Max & Min & Mean & CV & The Best Lines \\
\hline TKW & 53.35 & 23.55 & 41.56 & 12.24 & 15,41 and 44 \\
PC & 14.48 & 10.43 & 12.37 & 6.98 & 11,57 and 28 \\
ZSDS & 35.50 & 12.00 & 21.81 & 22.49 & 166,150 and 165 \\
MPTi & 3.87 & 0.89 & 1.82 & 23.05 & 106,103 and 22 \\
MPV & 68.29 & 34.43 & 54.13 & 9.12 & 50,167 and 53 \\
MTxV & 42.27 & 6.34 & 23.64 & 40.09 & 180,163 and 106 \\
MTxI & 336.44 & 154.36 & 268.66 & 11.20 & 29,50 and 22 \\
WS & 5.45 & 1.13 & 2.20 & 32.73 & 103,106 and 22 \\
\hline & & & & & Cultivars \\
\hline Traits & Max & Min & Mean & CV & The Best Cultivars \\
\hline TKW & 51.93 & 38.75 & 46.13 & 9.45 & Konya-2002, Tekirdag, Mufitbey \\
PC & 12.29 & 10.64 & 11.26 & 3.49 & Kirik, Dagdas-94 and Zencirci-2000 \\
ZSDS & 30.75 & 19.50 & 22.99 & 10.95 & Bezostaja-1, Kirik and Harmankaya-99 \\
MPTi & 3.84 & 1.84 & 2.54 & 17.95 & Flamura-85, Harmankaya-99 and Tekirdag \\
MPV & 62.83 & 48.90 & 56.46 & 5.86 & Demir-2000, Seval and Mufitbey \\
MTxV & 36.32 & 6.72 & 18.09 & 58.07 & Bayraktar-2000, Harmankaya-99 and Flamura-85 \\
MTxI & 313.39 & 263.67 & 290.58 & 4.68 & Demir-2000, Mufitbey and Seval \\
WS & 5.69 & 1.55 & 3.46 & 34.90 & Harmankaya-99, Bezostaja-1 and Seval \\
\hline
\end{tabular}

[\$: The best genotypes had the highest values each trait except MTxV; TKW: Thousand grain weight (g); ZSDS: Zeleny sedimentation test volume $(\mathrm{ml})$; PC: protein content $(\%)$; MPV: midline peak value $(\%)$; MTxV: midline time $\mathrm{x}=8$ min value $(\%)$; MTxI: midline time $\mathrm{x}=8 \mathrm{~min}$ integral $(\mathrm{Tq} \% * \min )$; MPTi: midline peak time (min); WS: weakening slope (min); CV: Coeffient of variation $(\%)]$

Regarding cultivars; the CV \% of the traits varied from $3.49 \%$ (for PC) to $58.07 \%$ (for MTxV). The lowest CV values were observed for the traits PC followed by MTxI,
MPV, and TKW indicating the least variation among the all cultivars for these characters, while the highest $\mathrm{CV}$ values were found for the MTxV, WS, MPTi and ZSDS (Table 1). 


\section{Relationship between traits}

Biplot procedure was used to evaluation relationships between studied traits. The GT biplots revealed the interrelationships between traits and it was also used as independent selection criteria based on several traits (Yan and Kang 2003; Akcura 2011). The cosine of the angle between two traits approximates the correlation between them; therefore, associations between all traits can be easily visualized from the biplot. Two traits were positively correlated if the angle between their vectors was $<90^{\circ}$, negatively correlated if the angle was $>90^{\circ}$, independent if the angle was $90^{\circ}$ (Yan 2014).

The genotype by trait (GT) biplot explained $67 \%$ (Figure 2), genotype-group (GGT) biplot explained $92 \%$ (Figure 3) of the total variation of the standardized data. Therefore, according to these results fundamental patterns among the traits should be captured by both genotype trait biplot (Figure 2) and genotype group trait biplot (Figure 3). The most prominent relations shown by genotype (group) trait biplot were: (i) a close correlation between WS and
MPTi as indicated by the near perpendicular vectors, (ii) a positive relation between ZSDS and MTxI, (Figure 2 and 3) and between MPV and PC in addition to between MTxV and PC (Figure 3), (iii) a negative association between TKW and all studied traits and between MTxV and other traits (Figure 2) except PC (Figure 3). Although these results usually reflected the correlation among the measured traits (Table 2), the biplot does not explain all of the variation in a dataset. WS exhibited significantly positive correlation with MPTi ( $\mathrm{r}=0.74 * *)$. These traits also positively associated with ZSDS $(\mathrm{r}=0.49 * *)$, MTxI $(\mathrm{r}=0.39 * *)$ and MPV $(\mathrm{r}=0.17 * *)$. MTxI had positive correlations with PC ( $\left.\mathrm{r}=0.29^{* *}\right), \mathrm{ZSDS}\left(\mathrm{r}=0.67^{* *}\right), \mathrm{MPV}$ $(\mathrm{r}=0.74 * *)$ as well as WS ( $\mathrm{r}=0.39 * *)$ and MPTi $(\mathrm{r}=0.47 * *)$. MTxV shows negative correlation with MPTi and WS (Table 2). Since the cosine of the angles does not precisely translate into correlation coefficients, some associations with traits couldn't be seen in biplots. So that between MTxV and other traits were not evaluated in biplots.

Table 2. Pearson correlation coefficient between quality traits $(n=225)$

\begin{tabular}{cccccccc}
\hline Traits & PC & ZSDS & MPTi & MPV & MTxV & MTxI & WS \\
\hline TKW & $-0.50^{* *}$ & $-0.23^{* *}$ & 0.02 & $-0.13^{*}$ & -0.11 & -0.10 & 0.09 \\
PC & & $0.41^{* *}$ & -0.04 & $0.27^{* *}$ & $0.22^{* *}$ & $0.29^{* *}$ & -0.10 \\
ZSDS & & & $0.63^{* *}$ & $0.47^{* *}$ & 0.03 & $0.67^{* *}$ & $0.49^{* *}$ \\
MPTi & & & $0.16^{*}$ & $-0.20^{* *}$ & $0.47^{* *}$ & $0.74^{* *}$ \\
MPV & & & & & $0.18^{* *}$ & $0.74^{* *}$ & $0.17^{* *}$ \\
MTxV & & & & & & -0.01 & $-0.19^{* *}$ \\
MTxI & & & & & & & $0.39^{* *}$ \\
\hline
\end{tabular}

[*: P<0.05; **: P<0.01; TKW: Thousand grain weight (g); ZSDS: Zeleny sedimentation test volume (ml); PC: protein content (\%); MPV: midline peak value (\%); MTxV: midline time $\mathrm{x}=8 \mathrm{~min}$ value $(\%)$; MTxI: midline time $\mathrm{x}=8$ min integral (Tq\%*min); MPTi: midline peak time (min); WS: weakening slope (min)]

\section{Classification of Genotypes}

Cluster analysis was done to classification of genotypes for studied traits (Table 3). The results of classification for bread wheat genotypes by hierarchical cluster analysis were given in Figure 4. Clustering of the 200 bread wheat pure lines, along with the 25 cultivars, was truncated at the tengroup level which retained $92.0 \%$ of the genotype-by-trait SS. Group V, the first largest group contained 45 pure lines and a cultivar (Dogu-88), the second largest group III contained 24 pure lines and two cultivars (Konya-2002 and Kirgiz-95), the third largest group VI contained 25 pure lines and a cultivar (Gelibolu) while groups II, VIII, I, IX, $\mathrm{X}$ and IV the smallest groups, each consisted of 23, 21, 19, 15, 15 and 9 genotypes. As indicated in Figure 4, the cultivars were separate into six groups (group III, V, VI, VII, IX and X). Interestingly group IX contained only 3 pure lines and 12 check cultivars (Altay-2000, Bagci-2002, Bezostaja-1, Demir-2000, Flamura-85, Gun-91, Pehlivan, Kenanbey, Harmankaya-99, Seval, Sonmez-2000 and Tosunbey) (Figure 4). For each attribute the individual groups exhibited different ranges of distribution.

Genotypes in groups VII and VIII (including pure lines 11, 57 and 28) had the highest PC, ZSDS, MTxI and MTxV (Table 3 and Figure 3).

The highest MPTi and WS were found for genotypes in group IX [(including only 3 pure lines and 12 check cultivars (Altay-2000, Bagci-2002, Bezostaja-1, Demir2000, Flamura-85, Gun-91, Pehlivan, Kenanbey, Harmankaya-99, Seval, Sonmez-2000 and Tosunbey)] (Table 3, Figure 4 and 5). 
Table 3. Mean values studied traits for clusters across growing seasons

\begin{tabular}{lllllllll}
\hline Group & TKW & PC & ZSDS & MPTi & MPV & MTxV & MTxI & WS \\
\hline Cluster 1 $(\mathrm{n}=19)$ & 45.88 & 12.08 & 14.88 & 1.26 & 51.23 & 27.05 & 233.32 & 1.50 \\
Cluster 2 $(\mathrm{n}=23)$ & 39.40 & 12.03 & 18.34 & 1.52 & 49.51 & 21.39 & 233.49 & 1.68 \\
Cluster 3 $(\mathrm{n}=26)$ & 48.18 & 11.33 & 20.13 & 1.82 & 53.71 & 21.28 & 268.61 & 2.28 \\
Cluster 4 $(\mathrm{n}=9)$ & 45.54 & 11.34 & 20.02 & 1.93 & 49.48 & 16.95 & 256.00 & 2.57 \\
Cluster 5 $(\mathrm{n}=46)$ & 39.87 & 12.39 & 20.59 & 1.83 & 53.15 & 26.07 & 262.75 & 2.02 \\
Cluster 6 $(\mathrm{n}=26)$ & 43.88 & 12.42 & 24.42 & 1.88 & 59.65 & 30.50 & 297.99 & 2.28 \\
Cluster 7 $(\mathrm{n}=25)$ & 37.09 & 13.08 & 26.87 & 2.12 & 57.21 & 13.59 & 300.15 & 2.50 \\
Cluster 8 $(\mathrm{n}=21)$ & 36.61 & 13.49 & 28.18 & 2.20 & 57.99 & 34.06 & 297.26 & 2.74 \\
Cluster 9 $(\mathrm{n}=15)$ & 43.76 & 11.73 & 26.12 & 2.69 & 56.39 & 21.70 & 290.15 & 4.39 \\
Cluster 10 $(\mathrm{n}=15)$ & 45.25 & 11.28 & 23.87 & 2.42 & 55.14 & 11.51 & 282.96 & 3.08 \\
\hline
\end{tabular}

[TKW: Thousand grain weight (g); ZSDS: Zeleny sedimentation test volume (ml); PC: protein content (\%); MPV: midline peak value (\%); MTxV: midline time $\mathrm{x}=8 \mathrm{~min}$ value (\%); MTxI: midline time $\mathrm{x}=8 \mathrm{~min}$ integral (Tq\%*min); MPTi: midline peak time (min); WS: weakening slope (min)]

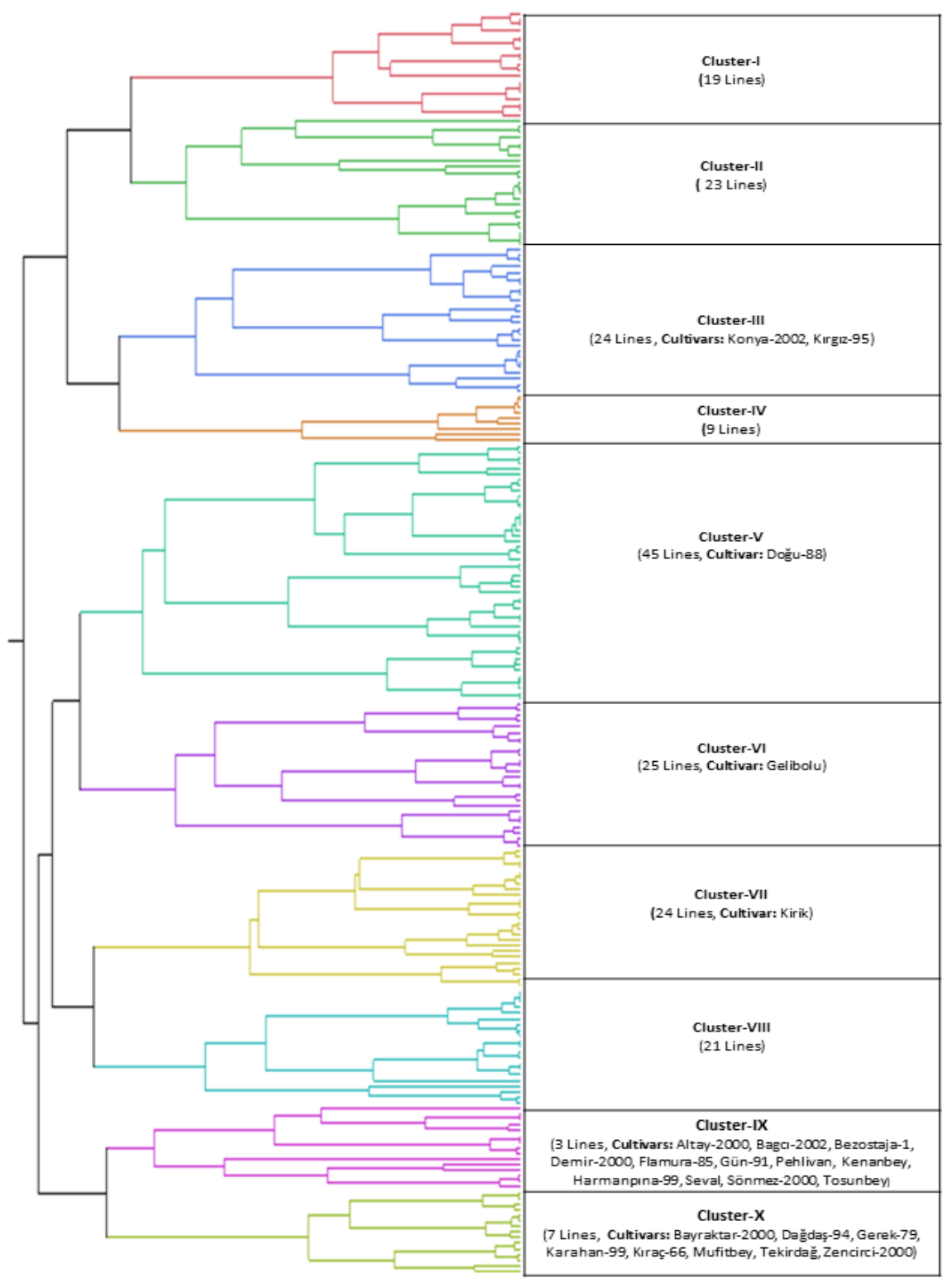

Figure 4. Grouping of 225 bread wheat genotypes (200 pure lines of landraces and 25 cultivars) based on 8 quality traits across growing seasons. 

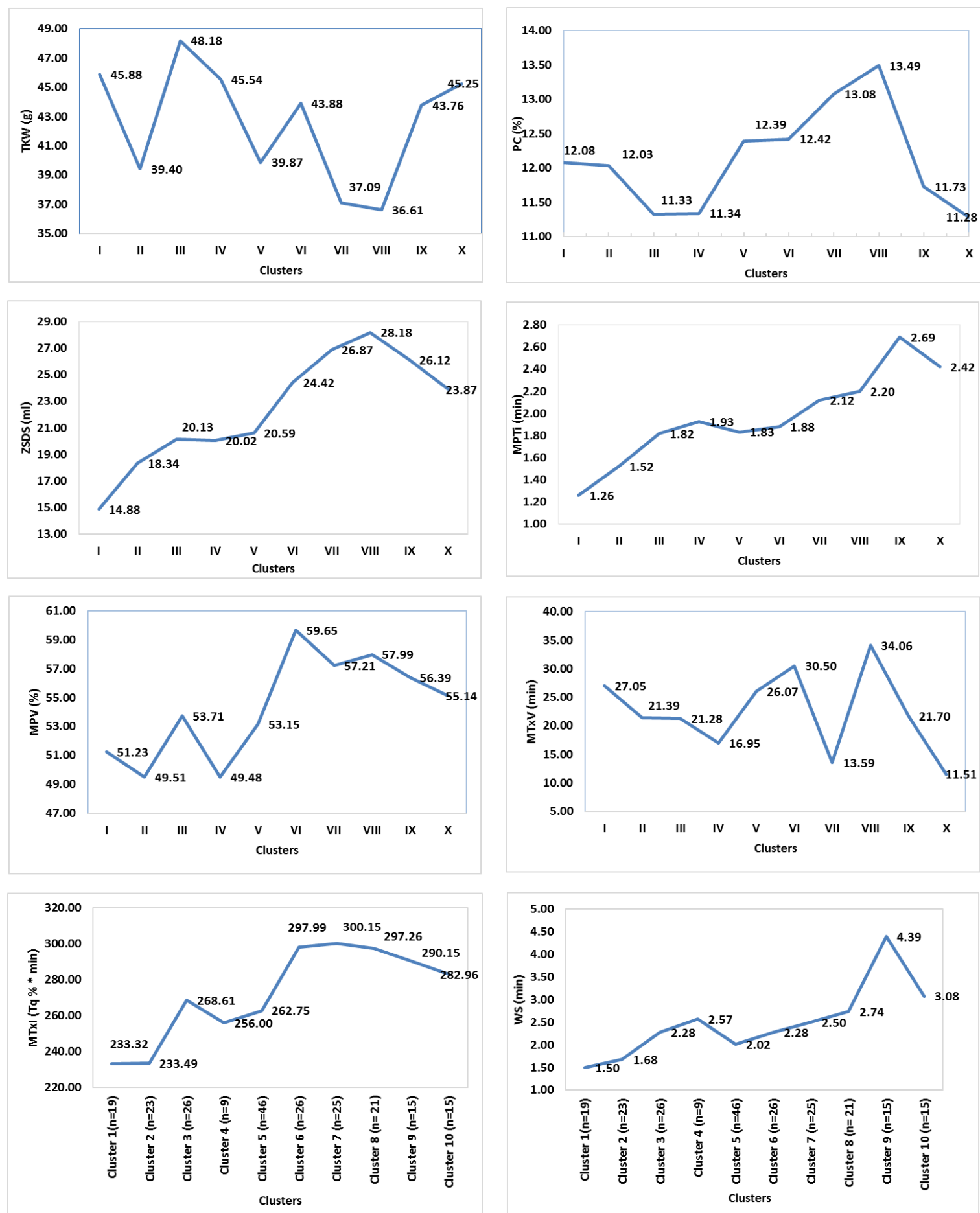

[TKW: Thousand grain weight (g); ZSDS: Zeleny sedimentation test volume (ml); PC: protein content (\%); MPV: midline peak value (\%); MTxV: midline time $\mathrm{x}=8 \mathrm{~min}$ value $(\%)$; MTxI: midline time $\mathrm{x}=8 \mathrm{~min}$ integral (Tq\%*min); MPTi: midline peak time (min); WS: weakening slope (min)]

Figure 5. Performance plots of 10 genotype clusters identified by cluster analysis for quality character.

\section{DISCUSSION}

Results of two growing seasons indicated a significant variation among the bread wheat genotypes, traits and their interactions. This is verified by the group of genotypes may be separated based on studied traits. High variation in the quality traits of genotypes was reflected by wide ranges for most of their genotypic characteristics. Variation for the genotypes could be also explained on the basis of the diverse geographic origins of these pure lines. Since most of studied quality traits are quantitative, the extensive variability among accessions was probably attributed to genetic differences as well as the environment where they were both regenerated and used (Morris 2009).

Additionally, the useful variability was estimated by comparing the variability of modern cultivars with those of other pure lines. Also, this was the first research on both 
quality and rheological characters of Turkish bread wheat landraces pure lines.

TKW is measure of the grain size and density; TKW and kernel number per square meter are the two main indicators of yield. The best pure lines 15 (ADIYAMAN TR 50465/4), 41 (ESKISEHIR TR 57999/2) and 44 (ESKISEHIR TR 55155/2) were the highest TKW values, $53.35 \mathrm{~g}, 52.88 \mathrm{~g}$ and $52.00 \mathrm{~g}$, respectively (Figure 2) (Data not shown).

PC one of the most important qualities to be considered in bread wheat production, were important in determining the nutritional value of wheat, both for human and animal consumption, and were major determinants of baking quality (Bordes et al. 2008). Bread wheat quality was principally determined by PC and gluten strength. Genotype groups VII (including 24 pure lines and Kirik cultivar) and VIII (including 21 pure lines) were the vertex group in the same section with PC (Figure 2 and Figure 3). In our study, PC of pure lines ranged from 10.43-14.48\%. This range is valuable in bread wheat breeding programs. Pure lines in these two group, 11 (ADIYAMAN TR 50465/1), 57 (HAKKARI TR 47987/4) and 28 (EDIRNE TR 33257/3) had the highest protein content $14.48 \%$, $14.25 \%$ and $14.14 \%$, respectively. PC of cultivars ranged from $10.64 \%$ to $12.29 \%$ which was lower from pure lines. Among cultivars, Kirik (12.29\%), Dagdas - 94 (12.24\%) and Zencirci (11.64\%) gave the highest PC values (Data not shown).

ZSDS gives an idea of the bread volume, with value of $30 \mathrm{ml}$ generally being considered as the suitable volume for bread making (Rakszegi et al. 2008). The ZSDS values for the pure lines varied from $12.00 \mathrm{ml}$ to $35.50 \mathrm{ml}$. This means that qualities of some pure lines were the excellent according to Turkish bread wheat quality standards (Sahin et al. 2013). Genotype groups VII and VIII were the vertex group in Figure 2 and Figure 3. Among pure lines 166 (SIVAS TR 48067/6), 150 (SIVAS TR 53312/3) and 165 (SIVAS TR 53313/5) were the best of genotypes for Zeleny sedimentation value, $35.50 \mathrm{ml}, 32.75 \mathrm{ml}$ and $31.75 \mathrm{ml}$, respectively. In cultivars, the highest Zeleny sedimentation values were obtained from Bezostaja-1 (30.75 ml), Kirik (30.00 ml) and Harmankaya-99 $(28.75 \mathrm{ml})$ cultivars (Data not shown).

The mixograph supply information regarding rheological behavior of dough that was of utmost importance when flour was evaluated for a specific endproduct (Walker and Hazelton 1996). The shapes of the mixograph curve portray the rheological and functional properties of dough. The different mixograph curve heights give information about dough consistency while the curve width and weakening slope (WS) are indicators of mixing tolerance. The area under the middle curve refers to the dough strength (Martinant et al. 1998; Bordes et al. 2008). In addition, mixogram curve obtained from mixograph gives an information on optimum dough development time (peak time), dough strength (peak height), dough development (ascending part), tolerance to over-mixing (descending part) and dough stability (slopes or angles created by the two arms) of the mixogram (Walker and Hazelton 1996; Walker et al. 1997).

In bread wheat breeding programs the MPTi values of standard wheats $\geq 2.0$ minute are considered as good quality; the values for the extra strong wheat are higher than 2.7 minute. Genotype groups IX and $\mathrm{X}$ were the vertex genotype groups in Figure 2 and Figure 3 in the same section with MPTi. For pure lines, MPTi value ranged from $0.89 \mathrm{~min}$ to $3.87 \mathrm{~min}$ that (Table 1) was found to be highest in 106 (KONYA Aksehir-36/18) 103 (KONYA Doganhisar-33/13) and 22 (BOLU TR 36948/5), $3.87 \mathrm{~min}$, $3.08 \mathrm{~min}$ and $2.99 \mathrm{~min}$, respectively. Among cultivars Flamura-85 (3.84 min), Harmankaya-99 (3.10 min) and Tekirdag (3.07 $\mathrm{min}$ ) showed the highest MPTi values.

For MPV of hard wheat a value of $\geq 60 \%$ was generally regarded as good quality for bread making. In addition, MPV of soft wheat of value had generally lower than hard bread wheat (Sahin et al. 2013). Genotype group VI had the highest mean value of MPV. In pure lines, MPV ranged from $34.43 \%$ to $68.29 \%$ found to be highest in 50 (GUMUSHANE TR 46871/1), 167 (SIVAS TR 48062/1) and 53 (HAKKARI TR 46763/1), 68.29\%, 65.60\% and $64.24 \%$, respectively. Among cultivars Demir-2000 (62.83\%), Seval (61.35\%) and Mufitbey (61.20\%) had the highest MPV values.

High MTxI value of bread wheat was generally evaluate good quality. In pure lines, MTxI ranged from 154.36 $\mathrm{Tq} \% * \min$ to $336.44 \mathrm{Tq} \% * \min$ found (Table 1) to be the highest in 29 (EDIRNE TR 33419/550), 50 (GUMUSHANE TR 46871/1) and 22 BOLU TR 36948/5, $336.44 \mathrm{Tq} \% * \min , 333.19 \mathrm{Tq} \% * \min$ and $329.14 \mathrm{Tq} \% * \min$, respectively. In cultivars, the highest MTxI values was observed from Demir-2000 (313.39 Tq\%*min), Mufitbey (312.49 $\mathrm{Tq} \% * \min )$ and Seval $(307.54 \mathrm{Tq} \% * \min )$ cultivars (Data not shown).

Generally, low MTxV value indicated high quality bread wheat (Sahin et al. 2011). Genotype group X had the lowest mean MTxV value. Among pure lines MTxV ranged from 6.34 to 42.27 found (Table 1) to the lowest in 163 (SIVAS TR 53318/5), 180 (VAN TR 45938/5), and 106 (KONYA Aksehir-36/18), 6.34\%, 6.49\% and 7.34\%, respectively. In cultivars the lowest MTxV values obtained Harmankaya-99 (6.72\%), Bayraktar-2000 (6.89\%), and Famura-85 (7.89\%) cultivars (Data not shown).

Although low MTxV value indicated high quality bread wheat, high WS value expressed a high mixing tolerance was usually evaluated as quality bread wheat (Sahin et al. 2013). For pure lines, the WS values ranged from $1.13 \mathrm{~min}$ to $5.45 \mathrm{~min}$ which was found to be the highest in 103 (KONYA Doganhisar-33/13) 106 (KONYA Aksehir36/18) and 22 (BOLU TR 36948/5), $5.45 \mathrm{~min}, 5.34 \mathrm{~min}$ and 4.97 min, respectively. Among cultivars Harmankaya-99 (5.69 min), Bezostaja-1 (5.25 min) and Seval (5.17 min) had highest WS values (Data not shown).

Correlation coefficients were computed to analyze the relationships between grain quality traits and dough properties and those that were significant were given in 
Table 2. The negative correlation observed between TKW and PC, ZSDS test and MPV. Our correlation coefficients between TKW and PC or dough properties were similar to those reported by Bordes et al. (2008) for 372 bread wheat's core collection. In addition, previous studies carried out for both bread wheat cultivars and landraces generally showed a negative relationship between thousand kernel weight with protein content and sedimentation (Peterson et al. 1992; Akcura 2011).

The correlation between protein content and ZSDS, MPV, MTxV, and MTxI were positively significant $(\mathrm{P}<0.01)$. The correlation between PC with MPTi and WS were negatively insignificant (Table 2, Figure 2 and Figure 3). Similar results between PC and ZSDS and sedimentation tests were reported by Hruskova and Oldrich (2003), Rakszegi et al. (2008) and Akcura (2011). Bordes et al. (2008) and Miles et al. (2013) obtained similar results, between PC and some mixograph parameters with different set of bread wheat genotypes. Martinant et al. (1998) reported a negative correlation between PC and MPTi.

Both higher gluten content and a better gluten quality gave rise to slower sedimentation and higher ZSDS values (Hruskova and Oldrich 2003). The higher SDS sedimentation volume, the more would be the strength of the protein (Williams et al. 1986). As it might be expected, ZSDS exhibited very strong positive relationships with all mixograph parameters except MTxV. Our findings were in line with the earlier findings of other investigators found correlations between SDS-sedimentation volumes and several mixogram parameters like Dobraszczyk and Schofield (2002), Konopka et al. (2004), Dobraszczyk and Salmanowicz (2008). The correlation between MPTi and other mixograph parameters were positively highly significant except MTxV, consistent with same findings by Martinant et al. (1998) and Neacsu et al. (2009).

The parameter MPTi exhibited significantly positive correlations with most of the investigated traits (MPV, MTxI and WS) except MTxV. Similarly, Martinant et al. (1998) who reported total area under curve (TA) to be the parameter most positively correlated with others. As expected, MTxV negatively significantly correlated with WS (Figure 2 and 3). In addition, there was significant positive correlation between MTxI and WS. Chung et al. (2001) reported significant correlations between protein content and MTxI, between MTxV and MTxI and between loaf volume and MTxI.

The biplot technique was used as a useful statistical tool for visualizing genotype-by-trait data and helped correctly for showing interrelationships among the traits. Figure 2 and 3 also shows the trait profiles of the genotypes, which is the basis of the correlations among traits (Yan 2014). It provided a tool for visual comparison among genotypes on the basis of multiple traits. The biplot also could be used in independent culling based on multiple traits and in comparing selection strategies (Yan and Kang 2003). The vertex genotypes in biplot could be characterized for specific attributes, while those near to origin of biplot could be considered as genotypes characterized for a wide range of attributes (Aghaee et al. 2010). Based on the trait relationships, different group of traits with different responses in discrimination of pure lines were identified. The pure lines 22 (BOLU TR 36948/5), 50 (GUMUSHANE TR 46871/1), 55 (HAKKARI TR 47982/5), 92 (KONYA Derbent-19/3), 103 (KONYA Doganhisar-33/13), 106 (KONYA Aksehir-36/18), 150 (SIVAS TR 53312/3) and 166 (SIVAS TR 48067/6) showed good performance based on the most of studied quality traits except TKW (Figure 2). The pure lines best responsed for TKW were 15 (ADIYAMAN TR 50465/4), 41 (ESKISEHIR TR 57999/2) and 83 (KONYA Seydisehir-10/16) (Figure 2). Especially, the Figure 2 showed the trait profiles of the genotypes, they were placed farther away from the biplot origin. For example, pure line 166 (SIVAS TR 53313/5) was found to be high for PC and MPV but low for TKW; pure line 15 (ADIYAMAN TR 50465/4) was high for TKW while low for PC and MPV; and pure line 106 (KONYA Aksehir-36/18) was both high for WS and MPTi. The cultivars Harmankaya-99, Bezostaja-1, Flamura-85, Pehlivan, Gun-91, Karahan-99, Bagci-2002, Mufitbey and Sonmez-2001 were the best for WS, MPTi, ZSDS, and MTxI. It can be seen from Figure 1 two attributes (PC and MPV) of cultivars were smaller than most of pure lines. Biplot technique to discriminate genotypes is applied based on traits used in different crops. For instance, this methodology was applied in wheat (DeLacy et al. 2000; Aghaee et al. 2010), soybean (Yan and Kang 2003; Cicek et al. 2006), white lupin (Rubio et al. 2004) and oat (Peterson et al. 2005; Yan and Frégeau-Reid 2008).

Regarding genotypes group VII and VIII had the highest values of PC, ZSDS and MTxI (Figure 5). These two groups including totally 45 pure lines and Kirik cultivar showed both high grain quality and rheology traits. Therefore, they might be more suitable for breeding high quality bread wheat cultivars.

\section{CONCLUSION}

In conclusion, pure lines of bread wheat landraces from seven geographical regions of Turkey were proved to be highly diverse for 8 traits of quality values (mixograph and grain quality) to breeders and as well as end-users. Also, our results may be very useful in choosing the precious pure lines or pure line group in further breeding programs (Figure 3, 4 and 5). In addition, results of pure line classification revealed that pure lines within each cluster belonged to different regions of Turkey which suggested that there was no clear relationship between pure lines and regional diversity. Therefore, more emphasis has to be directed at pure lines level rather than regional level as the source of diversity in this germplasm.

Although based on both grain quality and mixograph measurements, cultivars and pure lines showed some similarities, most of pure lines demonstrated higher PC, MPV, MTxI and ZSDS values than some of cultivars. The information, thus, obtained will be informative for wheat breeders, millers and bakers for their intended use. 


\section{ACKNOWLEDGMENTS}

This research was funded by the Scientific and Technological Research Council of Turkey (TUBITAK, project number $111 \mathrm{O} 255)$. The authors thank TUBITAK for the financial support.

\section{LITERATURE CITED}

Aghaee, M., R. Mohammadi and S. Nabovati. 2010. Agromorphological characterization of durum wheat accessions using pattern analysis. Aust J Crop Sci 4 505-514

Ahmadizadeh, M., H. Shahbazi, M. Valizadeh and M. Zaefizadeh. 2011. Genetic diversity of dururm wheat landraces using multivariate analysis under normal irrigation and drought stress conditions. Afr J Agric Res 6(1):2294-2302

Akcura, M. 2006. Characterization of Turkish winter bread wheat landraces genetic resource. PhD. Thesis. Selcuk University Graduate School of Natural and Applied Sciences, p 226. (in Turkish)

Akcura, M. 2009. Genetic variability and interrelationship among grain yield and some quality traits in Turkish winter durum wheat landraces. Turk J Agric For 33:547-556.

Akcura, M. and A. Topal. 2006. Phenotypic variability of Turkish winter bread wheat landraces. J of Plant Res 2:8-16 (in Turkish).

Akcura, M. 2011. The relationships of some traits in Turkish winter bread wheat landraces. Turk J Agric For 35(2):115125.

AACC 2000. Approved Methods of the American Association of Cereal Chemists, 10th ed. Methods 08-01, 44-15A, 46-11A. American Association of Cereal Chemists AACC, St Paul, MN, USA

Bardsley, D. and I. Thomas. 2005. Valuing local wheat landraces for agrobiodiversity conservation in Northeast Turkey. Agric Ecos Environ 106:407-412.

Belay, G., T. Tesemma, E. Bechere and D. Mitiku. 1995. Natural and human selection for purplegrain tetraploid wheats in the Ethiopian highlands. Genet Resour Crop Ev 42(4):387-391.

Bordes, J., G. Branlard, FX. Oury, G. Charmet and F Balfourier. 2008. Agronomic characteristics, grain quality and flour rheology of 372 bread wheats in a worldwide core collection. J Cereal Sci 48: 569-579.

Brush, S.B. and E. Meng. 1998. Farmers' valuation and conservation of crop genetic resources. Genet Resour Crop Ev 45:139-150.

Chung, O.K., J.B. Ohm, M.S. Caley and B.W. Seabourn. 2001. Prediction of baking characteristics of hard winter wheat flours using computer analysed mixograph parameters. Cereal Chem 78: 493-497.

Cicek, M.S., P.S. Chen, S.M. and G.R. Maroof Buss. 2006. Interrelationships among agronomic and seed quality traits in an interspecific soybean recombinant inbred population. Crop Sci 46:1253-1259.

DeLacy, I.H., M. Cooper and K.E. Basford. 1996. Relationships among analytical methods used to study genotype-byenvironment interactions and evaluation of their impact on response to selection. In 'Genotype-by-environment interaction'. (Eds MS Kang, HG Gauch) pp. 51-84. CRC Press: Boca Raton, FL.

DeLacy, I.H., B. Skovmand and J. Huerta. 2000. Characterization of Mexican wheat landraces using agronomically useful attributes. Genet Resour Crop Ev 47: 591-602.

Dobraszczyk, B.J. and B.P. Salmanowicz. 2008. Comparison of predictions of baking volume using large deformation rheological properties. J Cereal Sci 47(2) 292-301.

Dobraszczyk, B.J. and J.D. Schofield. 2002. Rapid assessment and prediction of wheat and gluten baking quality with the 2- $\mathrm{g}$ direct drive mixograph using multivariate statistical analysis. Cereal Chem 79: 607-612.

Flores, F., M.T. Moreno and J.I. Cubero. 1998. A comparison of univariate and multivariate methods to analyze $\mathrm{G} \times \mathrm{E}$ interaction. Field Crops Res 56: 271-286.

Gabriel, K.R. 1971. The bi-plot-graphical display of matrices with application to principal component analysis. Biometrika 58: 453-467.

Gokgol, M., 1939. Turkish wheat. Istanbul (in Turkish).

Harch, B.D., K.E. Basford, I.H. DeLacy, P.K. Lawrence and A. Cruickshank. 1995. Patterns of diversity in fatty acid composition in the Australian groundnut germplasm collection. Genet Resour Crop Ev 42: 234-256.

Hruskova, M. and F. Oldrich. 2003. Prediction of wheat and flour Zeleny sedimentation value using NIR technique. Czech J Food Sci 21(3): 91-96.

Ilker, E., F.A. Tonk, O. Caylak, M. Tosun, I. Ozmen. 2009. Assessment of genotype $\mathrm{x}$ environment interactions for grain yield in maize hybrids using AMMI and GGE biplot analyses. Turk J Field Crops 14(2): 123-135.

Ilker, E., H. Geren, R. Unsal, I. Sevim, F.A. Tonk and M. Tosun. 2011. AMMI-biplot analysis of yield performances of bread wheat cultivars grown at different locations. Turk J Field Crops 16(1): 64-68.

IRRI, 2013. International Rice Research Institute. CROPSTAT software 7.0.2.03 for Windows. Manila, Philippine. http://bbi.irri.org/products.

Jahufer, M.Z.Z., M. Cooper and B.D. Harch. 1997. Pattern analysis of the diversity of morphological plant attributes and herbage yield in a world collection of white clover (Trifolium repens L.) germplasm characterized in a summer moisture stress environment of Australia. Genet Resour Crop Ev 44: 289-300

Jaradat, A.A. 2006. Phenotypic divergence in the meta-population of the Hourani wheat landrace. J Food Agric Env 4:186-191.

Kara, B. and Z. Akman. 2007. Correlation and path coefficient analysis in the local wheat ecotypes. J Natur and Applied Sci 11(3):219-224 (in Turkish).

Karagoz, A. 2013. Wheat Landraces of Turkey. Emir J Food Agric 26 (2): 93-118.

Karcicio, M. and A. Izbirak. 2003. Isozymes variations in some Aegilops L. and Triticum L. species collected from Central Anatolia. Turk J Bot 27:433-440.

Kempton, R.A. 1984. The use of bi-plots in interpreting variety by environment interactions. J Agric Sci 103: 123-135.

Konopka, I., L. Fornal, D. Abramczyk, J. Rothkaehl and D. Rotkiewicz. 2004. Statistical evaluation of different technological and rheological tests of Polish wheat varieties for bread volume prediction. Int J Food Sci Tech 39(1): 1120.

Lipkovich, I.A. and E.P. Smith. 2002. Biplot and Singular Value Decomposition Macros for Excel. J Stat Softw 7(5):1-15.

Martinant, J.P., Y. Nicolas, A. Bouguennec, Y. Popineau, L. Saulnier and G. Branlard. 1998. Relationships between mixograph parameters and indices of wheat grain quality. $\mathrm{J}$ Cereal Sci 27: 179-189.

Miles, C.W., A., Van Biljon, W.M., Otto and M.T. Labuschagne. 2013. Grain and milling characteristics and their relationship with selected mixogram parameters in hard red bread wheat Int J Food Sci and Tech 39:11-20.

Morris, J.B. 2009. Characterization of sesame (Sesamum indicum L.) germplasm regenerated in Georgia, USA. Genet Resour Crop Ev 56: 925-936.

Neacsu, A., G. Stanciu, N.N. Sãulescu. 2009. Most suitable mixing parameters for use in breeding bread wheat for processing quality. Cereal Res Commun 37: 83-92. 
Ozbek, O. 2013. Turkish wheat landraces: Population structure and function. Emir Jour of Food and Agric 26(2): 137-148.

Ozbek, O., B.G. Taskin, S.K. San, V. Eser and O. Arslan. 2011. Gliadin polymorphism in Turkish cultivated emmer wheat (Triticum turgidum L. ssp. dicoccon (Schrank) Thell.) landraces. Plant Syst Evol 296(1-2):121-135

Ozbek, O., B.G. Taskin, S.K. San, V. Eser and O. Arslan. 2012. High-molecular-weight glutenin subunit variation in Turkish emmer wheat [Triticum turgidum L. ssp. dicoccon (Schrank) Thell.] landraces. Plant Syst Evol 298:1795-1804

Ozkan, H., Y. Avivi and M. Feldman. 1998. Variation of high molecular weight glutenin subunits in durum landraces of Turkey. In: A. A. Jaradat (Ed.) Triticeae III. Science Pub Inc.

Peskircioglu, M., S., Sehirali and M. Ozgen. 1998. Identification of wild diploid wheats of Turkey by gliadin electrophoresis. The Proceeding of International Symposium on in situ Conservation of Plant Genetic Diversity pp. 99-107.

Peterson, C.J., R.A. Graybosch, P.S. Baenziger and A.W Grombacher. 1992. Genotype and environment effects on quality characteristics of hard winter wheat. Crop Sci 32: 98103.

Peterson, D.M., D.M. Wesenberg, D.E. Burrup and C.A. Erickson. 2005. Relationships among Agronomic Traits and Grain Composition in Oat Genotypes Grown in Different Environments. Crop Sci 45:1249-1255.

Rakszegi, M., D. Boros, C. Kuti, L. Láng, Z. Bedo and P.R. Shewry. 2008. Composition and end-use quality of 150 wheat lines selected for the HEALTHGRAIN diversity screen. J Agr Food Chem 56(21):9750-9757.

Rosso, B.S. and E.M. Pagano. 2001. Collection and characterization of naturalized populations of white clover (Trifolium repens L.) in Argentina. Genet Resour Crop Ev 48: 513-517.

Rubio, J., J.I. Cubero, L.M. Martin, M.J. Suso and F. Flores. 2004. Biplot analysis of trait relations of white lupin in Spain. Euphytica 135: 217-224.
Sahin M., A. Gocmen Akcacik, S. Aydogan, S. Taner and R. Ayranci. 2011. Determination of relationships between bread volume and some physicochemical and rheological properties of bread wheat flour. J Field Crops Central Res Ins 20(1):611(in Turkish).

Sahin, M., A. Akcacik, S. Aydogan, Y. Kaya, B. Demir, H. Onmez and S. Taner. 2013. Determination of relationships between bread volume and some physicochemical and rheological properties of bread wheat flour. J Field Crops Central Res Ins 22 (1):13-19 (in Turkish).

Sayaslan, A., M. Koyuncu, A. Yıldırım, T. Eserkaya Gulec, O. Ates Sonmezoglu and N. Kandemir. 2012. Some quality characteristics of selected durum wheat (Triticum durum) landraces. Turk J Agric For 36:749-756.

Walker, C.E. and J.L. Hazelton. 1996. Dough rheological tests. Cereal Foods World 41: 23-28

Walker, C.E., A.E. Walker and J.L. Hazelton 1997. Computerising the mixograph: Data collection and analysis. Pages 39-43 in: The mixograph handbook. 1st edition. C.E. Walker, J.L. Hazelton and M.D. 50 Shogren, eds. National Manufacturing Division, TMCO, Lincoln, NE 68508-2935, USA.

Williams, W.T. 1976. Pattern analysis in agricultural science. Amsterdam. Elsevier Scientific Publishing Company.

Williams P.F., J. Haremein, H. Nakkoul, S. Rihawi. 1986. Crop quality evaluation methods and guidelines. ICARDA Aleppo, Syria.

Yan, W. and M.S. Kang. 2003. GGE Biplot Analysis: A graphical tool for breeders, geneticists, and agronomists. CRC Press, Boca Raton, FL.

Yan, W. and J. Fregeau-Reid. 2008. Breeding line selection based on multiple traits. Crop Sci 48: 417-423.

Yan, W. 2014. Crop variety trials: Data management and analysis. John Wiley and Sons. pp. 349. 